\title{
Optimization of shot peening for titanium alloys Ti 10-2-3 in CONDOR project
}

\author{
Corentin DIDES ${ }^{\mathrm{a}}$, Thomas BILLOT ${ }^{\mathrm{b}}$, Nicolas GUILLEMOT ${ }^{\mathrm{c}}$ \\ a IRT-M2P, 4 rue Augustin Fresnel 57000 Metz. \\ b SAFRAN LANDING SYSTEMS, 9 Rue Guynemer, 64400 Bidos. \\ c AIRBUS HELICOPTERS, Aéroport International Marseille-Provence 13725 Marignane Cedex.
}

\begin{abstract}
:
CONDOR is an R\&D project lead by IRT-M2P with different industrial partnership to increase knowledge and simulation models of shot peening. This surface hardening process aims to perform different shots with high velocity on metallic surfaces to introduce compressive stresses on it. Fatigue behavior of shot peened parts is significantly improved. During this research project a DOE has been carried out to optimize shot peening parameters on titanium alloys (surface roughness before shot peening, size and shot's hardness, covering and intensity). The DoE is composed by more than 300 fatigue specimens. All this data allows us to define specifically each shot peening parameter influence on shot penned parts efficiency. CONDOR project allows simulation development of models to simulate shot peening effect by taking into account the parameters introduced above. Those models are used to evaluate residual stress level and fatigue lifetime after shot peening and to confirm models readiness level. This study has defined optimized machining and shot peening conditions in order to increase parts fatigue lifetime.
\end{abstract}

\section{Introduction:}

IRT M2P is a French institute of research and technology which is working on metallic materials and surfaces treatments. CONDOR project is a research and development project about shot peening. Different topics have been developed in this project; optimization of shot peening of Ti 10-2-3 alloys is one of them. Today, shot peening on titanium parts is similar to steel parts and it appears that shot peening in those conditions can lead to fatigue abatement. Very few studies are available on the impact of shot peening on fatigue life of near beta titanium alloys. [1][2] In order to improve our understanding and to optimize shot peening of near Beta titanium alloys, a DOE has been performed with fatigue specimens (more than 300 four points fatigue bending specimens).

\section{Material and experiments:}

\section{Material:}

The material used for this study is the Ti 10-2-3 which belongs to near beta alloys family. [3]

\section{Design of Experiments:}

There are many parameters in shot peening: Incidence angle, velocity, shots type, Almen intensity, coverage, projection type [2]. In addition, before shot peening, the finishing operation of machining can have an influence on final fatigue life [4], in particular roughness.

5 parameters have been chosen to define optimal conditions for shot peening and surface preparation. In order to reduce the number of tests, 3 fatigue tests levels have been defined and included as a parameters of the Matrix. DOE parameters are presented in table 2.

Table 1 : DOE parameters

\begin{tabular}{|c|c|c|c|c|c|}
\hline $\begin{array}{c}\text { Roughness } \\
\text { after machining } \\
(\mathrm{Ra})\end{array}$ & $\begin{array}{c}\text { Stress level } \\
(\mathrm{MPa})\end{array}$ & $\begin{array}{c}\text { Shot Hardness } \\
(\mathrm{HRC})\end{array}$ & $\begin{array}{c}\text { Diameter } \\
(\mu \mathrm{m})\end{array}$ & $\begin{array}{c}\text { Intensity } \\
(\mathrm{A})\end{array}$ & $\begin{array}{c}\text { Coverage } \\
(\%)\end{array}$ \\
\hline 0.8 & Level 1 & - & - & - & - \\
\hline 1.6 & Level 2 & + & + & + & + \\
\hline 3.2 & Level 3 & \multicolumn{3}{|r}{} \\
\cline { 2 - 5 }
\end{tabular}


In these conditions, the DOE has 144 combinations. Considering tests' repetition to evaluate the scattering and also the additional specimens to characterize the microstructure, the amount of testes was too huge and needed to be reduced.

To do so, D-optimal methods have been used to optimize the DOE leading to a reduce plan of 325 testes.

Specimens preparation and testing conditions:

The specimens' geometry used for the four points bending fatigue tests is presented on figure 1. Both side of specimens have been shot peened in industrial Wheelabrator machine using nozzles on a 6 axes robot. Shot peening was performed with $85^{\circ}$ angle from the surface with a longitudinal direction displacement.
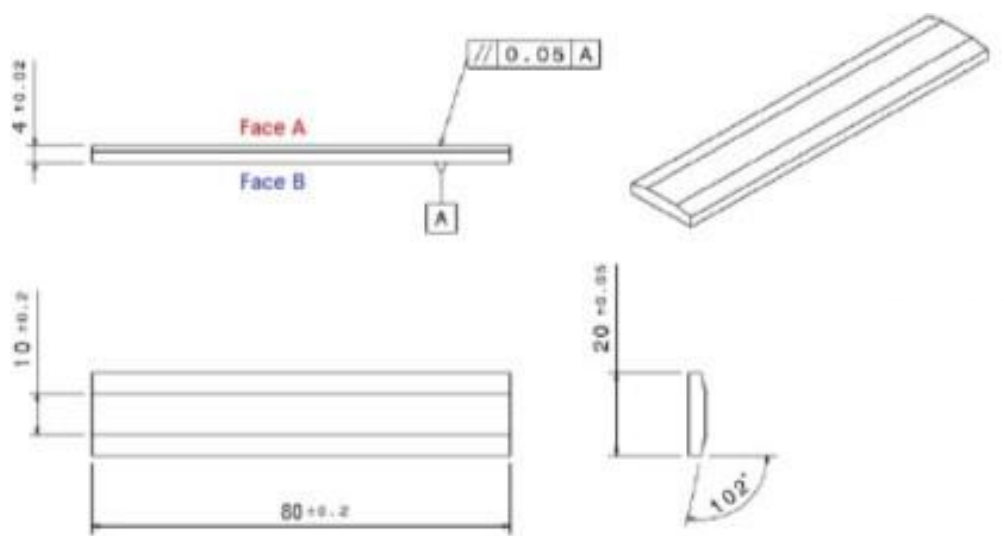

Figure 1 : Specimens shape

To start with similar microstructure, all specimens have been picked-up at mid radius of a billet. Face A corresponds to the face close to mid radius (see figure 2). The three roughness specified in the DOE Ra $=0.8 / 1.6$ / 3.2 are related to different machining conditions.

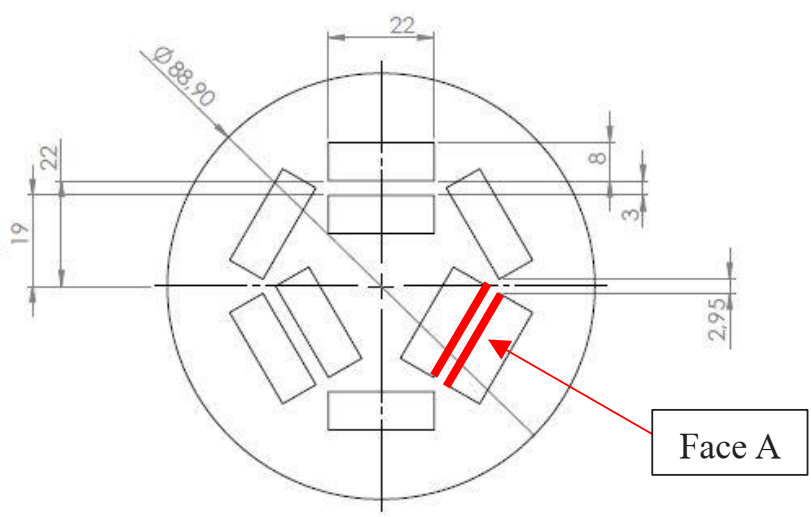

Figure 2: Cut plan for 4 points bending fatigue

All fatigue tests have been performed with the following conditions:

- $\quad$ Ratio: $\mathrm{R}=0.1$

- Controlled in maximum stress level

- Frequency: $10 \mathrm{~Hz}$

Results analysis has been performed with Minitab software. 


\section{Results:}

Today only third quarter of the DOE have been tested due to lack of time. All the results and conclusions will be presented at the conference in June.

Prior to shot peening test plan, several fatigue tests were launched on smooth specimens with different surface roughness to establish the reference. These results are plotted in figure 3.

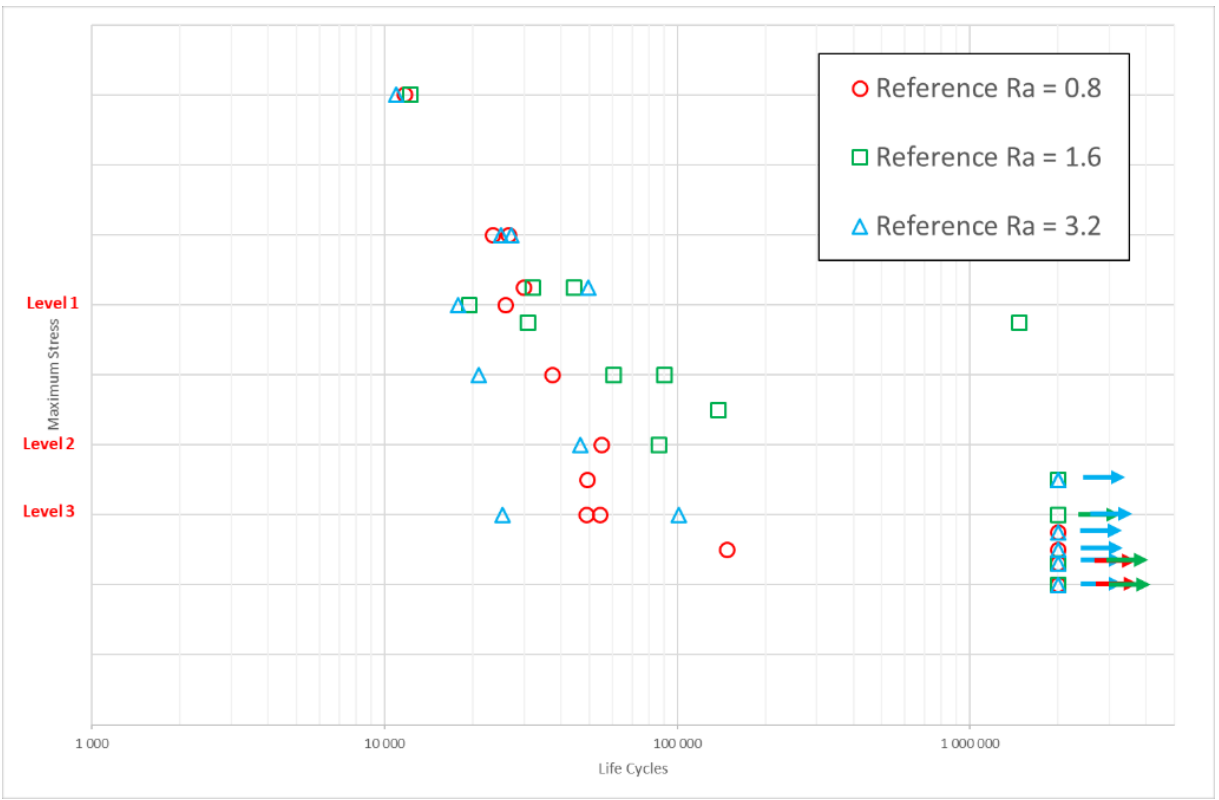

Figure 3: Wöhler curve of Ti 10-2-3 with three different surface roughness

It can be seen that surface roughness doesn't have significant effect on life. Close to the endurance scattering is more important and the impact of roughness is difficult to quantify. The three stress levels used for the DEO have been defined according to the reference testes in order to represent different parts of the Wöhler curve. Stress level close to endurance is avoided to present too much non-failed specimens, which couldn't be used for the analysis.

Pareto diagram has been used to evaluate the relative impact of each of parameter, or combination of parameters, on fatigue life (figure 4).

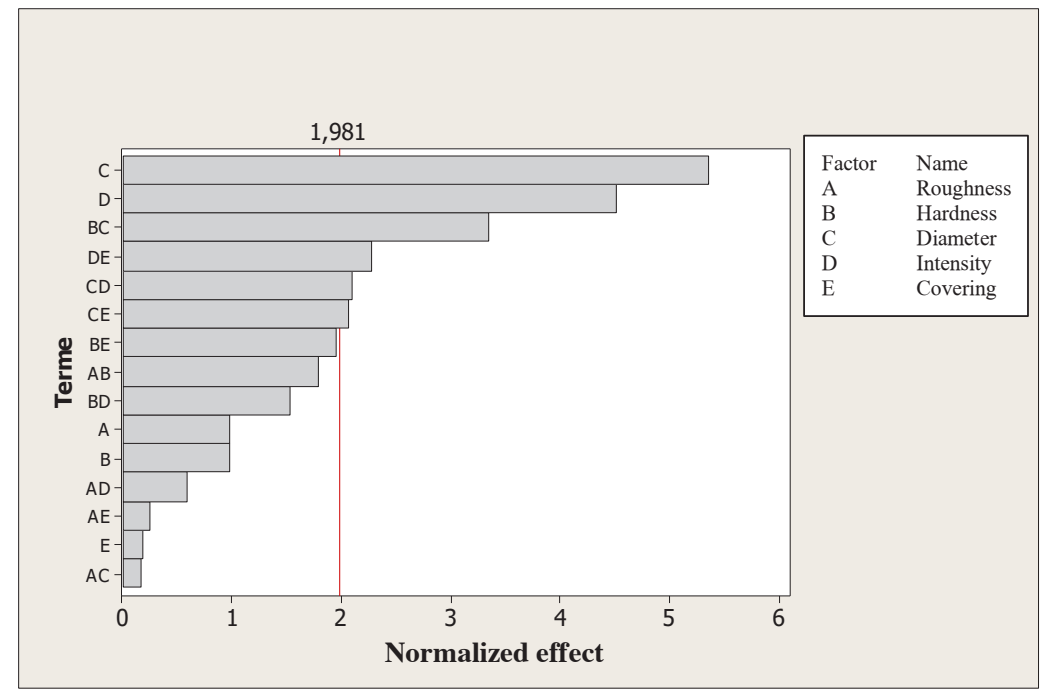

Figure 4: Pareto diagram of normalized effect

This analusis shows that the parameters, or combination of parameters, which present normalized effect above 1.981 have a significant impact on fatigue life. If it turns out that surface roughness before shot peening has very 
low impact on fatigue, shot parameters (diameter and hardness) and Almen intensity have much more influence on fatigue life.

In addition to Pareto analysis, the graphic of major effects represents the evolution of fatigue life with regard to parameters "low-high" limits (figure 5).

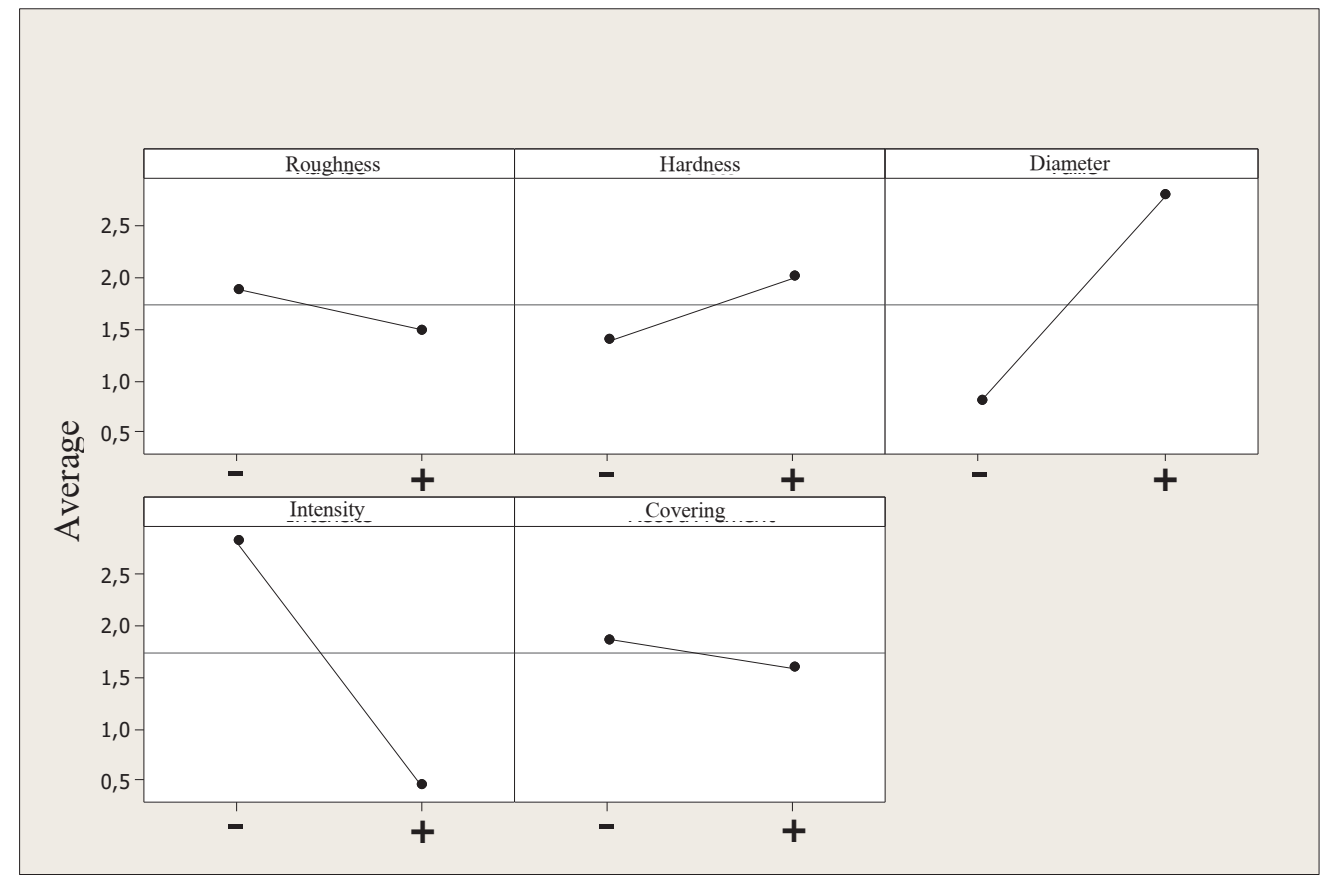

Figure 5: Graphic of major effects on fatigue life time enhancement

Size has a very important impact on fatigue enhancement, shots with large diameter have a benefic effect on fatigue life time. In contrast, the intensity has to be reduce to improve fatigue life. As it can be seen above on Pareto diagram Covering and Roughness before shot peening doesn't have strong effect on the results observed. Shot hardness has to be high but as for roughness and covering, it has just a few effect if it's take alone.

Pareto diagram shows that combinations of parameters can also have a strong impact on final results. Figure 6 is the diagram of interaction between the different parameters. 


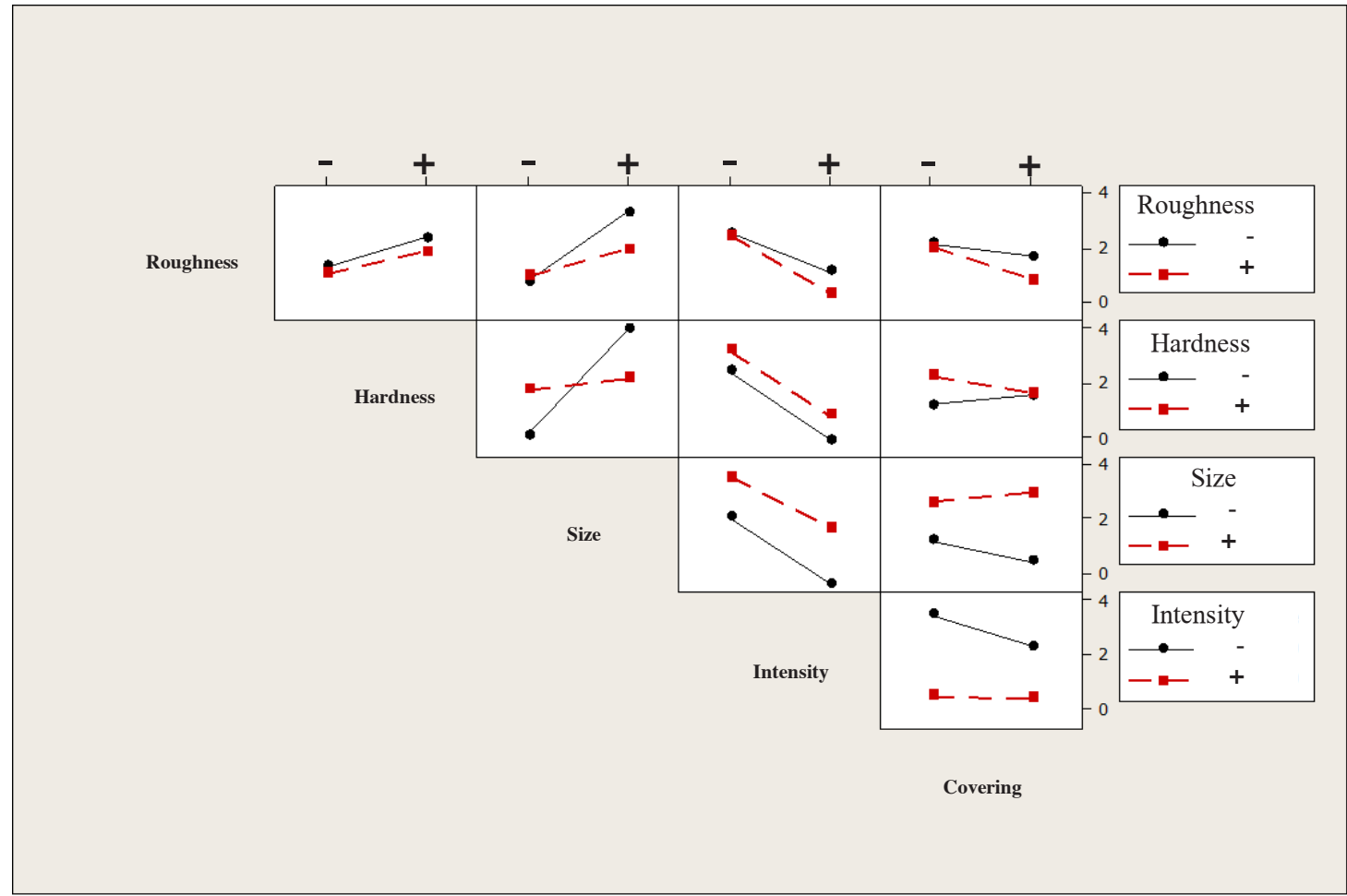

Figure 6: Diagram of parameters interactions regarding fatigue lifetime

First observation shows that except for hardness and shots size, for each combinations, curves do not cross each other. Whatever the parameter combined with the intensity, lower value provides the best response. As for intensity, size seems to be more efficient for large diameters for each combination. Only the hardness is strongly affected by the size and low hardness is better with size with large diameter size. Combination of covering with roughness and hardness has no impact on results. Otherwise, covering has an effect with low intensity and it seems damaging to use a too important amount of covering.

\section{Conclusions:}

Ti 10-2-3 titanium can't be easily shot peened like most of steel. Shot peening parameters have to be chosen very carefully.

Regarding the results, a low intensity with high diameter shots seems to have the best effects on fatigue behaviour. These results can be explained by the high sensitivity of titanium to the surface integrity (roughness, residual stresses \& hardening). In addition, a low Almen intensity can introduce enough residual stress without decreasing significantly the surface roughness. Experiment results with high shots size are in the same way because the more shot diameter is high, the more surface is homogenous and covering is quick.

Covering has an impact on fatigue results only for a low intensity. This observation seems to explain that high intensities seems to generate high roughness which has a more important impact on fatigue than compressive residual stresses. Besides, a too important covering downgrade the roughness and fatigue behaviour in the same way. This conclusion is consistent with some studies in the literature on fatigue behaviour of titanium parts [5].

Because some measurements haven't been performed yet, roughness and residual stress answers are not presented in this paper but will be added in the presentation. It will allow to understand all fatigue answers and competition between roughness and residual stress on titanium alloys. 


\section{References:}

[1] O. Unal, A.Cahit Karaoglani, R. Varol, A. Kobayashi, 2014, Microstructure evolution and mechanical behavior of severe shot peened commercially pure titanium: Vacuum 110, p.202-206.

[2] J. P. Fuhr, M. Basha, M. Wollmann, L. Wagner, 2018, Coverage and Peening Angle Effects in Shot Peening on HCF Performance of Ti-6Al-4V: Procedia Engineering 213, p.682-690.

[3] C. Deleuze, L. Barrallier, A. Fabre, C. Esberard, 2009, $19^{\text {ème }}$ Congrès Français de Mécanique, 24-28 août Marseille : Etude de la microstructure d'un alliage de titane biphasé de nuance Ti-10V-2Fe-3Al et de son influence sur l'élargissement des pics de diffraction.

[4] A. Cox, S. Herbert, J-P. Villain-Chastre, S. Turner, M. Jackson, 2019, The effect of machining and induces surface deformation on the fatigue performance of a high strength metastable Beta titanium alloy: International Journal of Fatigue 124, p.26-33.

[5] C. Yao, D. Wu, L. Ma, L.Tan, Z. Zhou, J. Zhang, 2016, Surface integrity evolution and fatigue evaluation after milling mod shot-peening and polishing mode for TB6 titanium alloy : Applied Surface Science 387, p.1257-1264. 